\title{
The Synthesis of 7-Substituted-3-dinitrostyryl Cephalosporins and Their Ability for Detecting Extended Spectrum $\beta$-Lactamases (ESBLs)
}

\author{
Hideaki Hanaki, Hiroaki Yamazaki, Hidenori Harada, Ryoichi Kubo, \\ Takayoshi Kobayashi, Koichiro Atsuda, Keisuke Sunakawa
}

Received: September 10, 2004 / Accepted: December 14, 2004

(C) Japan Antibiotics Research Association

\begin{abstract}
We synthesized 7-substituted-3-(2,4dinitrostyryl)cephalosporin derivatives which were Nitrocefin analogs, for detecting extended spectrum $\beta$ lactamase (ESBL) specifically. HMRZ-86 which has carboxypropyloxyimino group on 7 -aminothiazolacetamide substituent were not hydrolyzed by class $\mathrm{A}, \mathrm{C}$ and $\mathrm{D} \beta$ lactamases, but it was hydrolyzed by ESBL and metallo $\beta$ lactamase (class B), then its color changed from yellow to red. The hydrolysis of metallo $\beta$-lactamase was inhibited by adding sodium mercapto acetic acid (SMA). Therefore HMRZ-86 is a useful chromogenic agent to detect ESBL specifically.
\end{abstract}

Keywords ESBL, $\quad \beta$-lactamase, $\quad$ chromogenic, cephalosporin, HMRZ-86

$\beta$-Lactamase is an enzyme hydrolyzing $\beta$-lactam antibiotics which are very problematic in chemotherapy. Since an enzyme-producing pathogen resists antibiotics, an improvements was made on $\beta$-lactam antibiotics to escape to be attacked by $\beta$-lactamases.

However, 1980s onward, mutated $\beta$-lactamases have appeared and specified as extended spectrum $\beta$-lactamase (ESBL) and this new $\beta$-lactamase became very important for chemotherapy because they acquired an ability to hydrolyze the third generation cephem, such as ceftazidime and cefotaxime (Fig. 1a) [1]. Nitrocefin (Fig. 1b) [2] is the most popular chromogenic chephalosporin as a reagent for detecting of $\beta$-lactamase, but this compound is too sensitive to distinguish only those mutated $\beta$-lactamase from traditional ones. Most traditional detection methods for ESBL are based on cultivation [3], but whose demerits are labor intensive and time consuming procedure.

We have developed new chromogenic cephalosporin; (7R)-7-[2-(aminothiazol-4-yl)-(Z)-2-(1-carboxy-1-methylethoxyimino)acetamido]-3-(2,4-dinitrostyryl)-3-cephem-4carboxylic acid trifluoroacetate, $E$-isomer (HMRZ-86) (Fig. $1 \mathrm{c})$ for detecting the mutated $\beta$-lactamases specifically. A color of the compound was changed from yellow to red by
H. Hanaki: Research Center for Anti-infective Drugs, Kitasato Institure, 5-9-1, Shirokane, Minato-ku, Tokyo 108-8641, Japan H. Yamazaki (Corresponding author), H. Harada: Research Laboratory, Zenyaku Kogyo Co., Ltd. 2-33-7, Ohizumimachi, Nerima-ku, Tokyo 178-0062, Japan, E-mail: HiroakiYamazaki@mail.zenyaku.co.jp

R. Kubo, T. Kobayashi: Department of Life Science, Kanto Chemical Co., Inc. Nihonbashi Honcho 3 chome, Chuo-ku, Tokyo 103-0023, Japan
K. Atsuda: Center for Clinical Pharmacy and Clinical Sciences Division of Hopital Pharmacy, Kitasato University, 5-9-1, Shirokane, Minato-ku, Tokyo 108-8641, Japan

K. Sunakawa: Department of Infectious Disease, Kitasato University, 1-15-1, Kitasato, Sagamihara, Kanagawa 228-8555, Japan 
a)<smiles>CC(C)(C)O/N=C(/C(=O)N[C@H]1C(=O)N2C(C(=O)O)=C(C[n+]3ccccc3)CS[C@H]12)c1csc(N)n1</smiles>

Ceftazidime (CAZ)<smiles>CO/N=C(/C(=O)N[C@@H]1C(=O)N2C(C(=O)O)=C(OC(C)=O)CS[C@H]12)c1csc(N)n1</smiles>

Cefotaxime (CTX)

b)<smiles>O=C(Cc1cccs1)N[C@H]1C(=O)N2C(C(=O)O)=C(/C=C/c3ccc([N+](=O)[O-])cc3[N+](=O)[O-])CS[C@H]12</smiles>

Nitrocefin

c)<smiles>CC(C)(O/N=C(\C(=O)N[C@H]1C(=O)N2C(C(=O)O)=C(/C=C/c3ccc([N+](=O)[O-])cc3[N+](=O)[O-])CS[C@H]12)c1csc(N)n1)C(=O)O</smiles>

HMRZ-86

Fig. 1 a) Third generation chephems. b) Nitrocefin. c) (7R)-7-[2-(aminothiazol-4-yl)-(Z)-2-(1-carboxy-1-methylethoxyimino)acetamido]-3-(2,4-dinitrostyryl)-3-cephem-4-carboxylic acid trifluoroacetate, E-isomer (HMRZ-86).

hydrolysis of $\beta$-lactamase $[4,5]$.

In this paper, we outline a synthesizing procedure of the HMRZ-86 and similar compounds, and also biochemical reaction of those compounds for several $\beta$-lactamases.

\section{Mechanisms}

The HMRZ-86 has a carboxypropyloxyimino group bonded to 7 -aminothiazole acetamide to protect the $\beta$-lactam ring from $\beta$-lactamase, but not from mutated them such as ESBL or metallo $\beta$-lactamase. Hydrolysis of the $\beta$-lactam ring by these enzymes changes the wavelength absorbed by the conjugated double bond located at position 3 , and shifting the color of the compound from yellow to red.

\section{Synthesis of Chromogenic Cephalosporin}

Scheme 1 shows sketch of synthesizing process for HMRZ86 and similar compounds. Here "R" can be replaced substitutes "a" to "d" depending on compound, and substitute of HMRZ-86 is "a". A typical example of a synthesis procedure of HMRZ-86 is given here. At first 7-aminochloromethylcephalosporanic acid benzhydryl ester (1) with (Z)-2-(2-tritylaminothiazol-4-yl)-2-(1-tertbutoxycarbonyl-1-methyl)ethoxyimino acetic acid was amided using dicyclohexylcarbodiimide (DCC) and then (7R)-7-[(Z)-2-(1-methyl-1-tert-butoxycarbonylethoxyimino)-2-(2-tritylaminothiazol-4-yl)acetamido-3chloromethyl-3-cephem-4-carboxylic acid benzhydryl ester (2a) was synthesized. Next, the compound was treated with $\mathrm{NaI}$ and triphenylphosphine for 1.5 hours in acetone, and then evaporated. After the evaporation, the residue was dissolved in dichloromethane-water, then 2,4dinitrobenzaldehyde and sodium hydrogen carbonate $\left(\mathrm{NaHCO}_{3}\right)$ were added serially. And the mixture was stirred at room temperature for 1 day and the organic phase was recovered, and concentrated. After concentration, the crude compounds were separated by column chromatography using hexane-ethyl acetate and resulting 3dinitrostyrylcephem (3a). Protective group of the compound was removed by treatment with trifluoroacetic acid in the presence of anisole, then crude product was recrystallized from $70 \%$ acetonitrile to give $(7 R)-7-[2-$ (aminothiazol-4-yl)-(Z)-2-(1-carboyl-1-methylethoxyimino)acetamido]-3-(2,4-dinitrostyryl)-3-cephem-4carboxylic acid trifluoroacetate, $E$-isomer (4a): ${ }^{1} \mathrm{H}$ NMR 

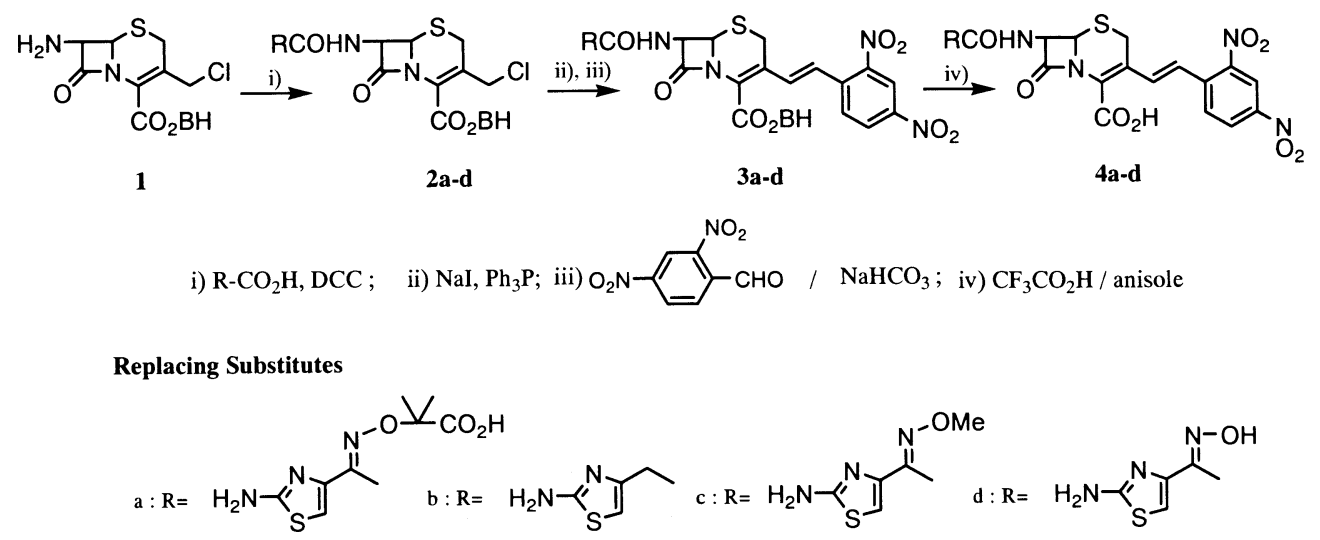

\section{Scheme 1}

$\left(270 \mathrm{MHz}, \mathrm{DMSO}-d_{6}\right) \delta 1.45\left(3 \mathrm{H}, \mathrm{s},-\mathrm{CH}_{3}\right), 1.46(3 \mathrm{H}, \mathrm{s}$, $\left.-\mathrm{CH}_{3}\right), 3.71\left(1 \mathrm{H}, \mathrm{d}, J=17.5 \mathrm{~Hz},-\mathrm{S}-\mathrm{CH}_{2}-\right), 4.04(1 \mathrm{H}, \mathrm{d}$, $\left.J=17.5 \mathrm{~Hz},-\mathrm{S}-\mathrm{CH}_{2}-\right), 5.30(1 \mathrm{H}, \mathrm{d}, J=5.0 \mathrm{~Hz}, 6-\mathrm{H}), 5.90$ $(1 \mathrm{H}, \mathrm{dd}, J=8.2 \mathrm{~Hz}, 5.0 \mathrm{~Hz}, 7-\mathrm{H}), 6.73(1 \mathrm{H}, \mathrm{s}$, thiazole- $\mathrm{H})$, $7.25(1 \mathrm{H}, \mathrm{d}, J=16.5 \mathrm{~Hz},-\mathrm{CH}=\mathrm{CH}-), 7.53(1 \mathrm{H}, \mathrm{d}, J=16.5$ $\mathrm{Hz},-\mathrm{CH}=\mathrm{CH}-), 7.97(1 \mathrm{H}, \mathrm{d}, J=8.7 \mathrm{~Hz}$, aromatic-H), 8.50 $(1 \mathrm{H}, \mathrm{dd}, J=8.7,2.3 \mathrm{~Hz}$, aromatic-H), $8.71(1 \mathrm{H}, \mathrm{d}, J=2.3$ $\mathrm{Hz}$, aromatic-H), $9.52(1 \mathrm{H}, \mathrm{d}, J=8.2 \mathrm{~Hz},-\mathrm{CONH}-)$.

Similarly, other chromogenic cephalosporins were synthesized using starters which position " $\mathrm{R}$ " is replaced as "b" to "d" groups.

\section{Materials and Methods}

\section{1) Chromogenic Cephalosporin Solutions}

$1.25 \mathrm{mg}$ of each synthesized compound was dissolved in $0.1 \mathrm{ml}$ of dimethylsulfoxide (DMSO) and diluted to $1 \mathrm{ml}$ by phosphate buffer (0.1 M, pH 7.0).

\section{2) Chromogenic Cephalosporin/Sodium Mercapto Acetic Acid (SMA)}

$1.25 \mathrm{mg}$ of SMA is added to each chromogenic cephalosporin solution.

\section{3) Dises}

Each $8 \mu \mathrm{l}$ or $16 \mu \mathrm{l}$ of diluted solution was added to $8 \mathrm{~mm}$ of paper discs, and dried for 30 minutes at $37^{\circ} \mathrm{C}$. Finally the disc contained 10 or $20 \mu \mathrm{g}$ of each chromogenic compound.

\section{4) Strains}

Characteristics of the tested strains and enzyme types are shown in Table 1. These strains were cultivated over night at $37^{\circ} \mathrm{C}$ on tryptone soy agar (Oxoid Ltd.) containing $2 \mathrm{mg} / \mathrm{l}$ of ceftazidime.

\section{5) Minimum Inhibitory Concentration (MICs)}

MICs were determined by broth microdilution testing method which was recommended by NCCLS [3].

\section{Results and Discussion}

Table 1 summarizes the antibacterial activities of the synthesized compound. All compounds were active against $\beta$-lactamase non-producing $S$. aureus and E. coli and penicillinase producing $S$. aureus and $K$. pneumoniae. However, all compounds were not active against other $\beta$ lactamases, including ESBL, producing strains.

Fig. 2 shows the reaction of the compounds with several mutated $\beta$-lactamases and ESBLs producing microorganisms. Ten or $20 \mu \mathrm{g}$ of the compounds were enough to identify the result according to a color change. Nitrocefin reacted with most of these $\beta$-lactamases. The compound (4a) which has carboxypropyloxyimino group as protected group for $\beta$-lactam ring reacted with ESBL, followed by a strong color change from yellow to red, and with metallo $\beta$-lactamases weakly, however it did not react with penicillinase, cephalosporinase and oxacillinase. Other compound (4c) has methoxyimino group and $\mathbf{4 d}$ has hydroxyimino group both of which reacted with ESBL and metallo $\beta$-lactamases and changing the color similarly to a case of $\mathbf{4 a}$, however, the two compounds $\mathbf{4 c}$ and $\mathbf{4 d}$ also reacted with penicillinase from Stapylococcus aureus and 
Table 1 In vitro antibacterial activity (MIC, $\mu \mathrm{g} / \mathrm{ml})$ of synthetic compounds $(\mathbf{4 a} \sim \mathbf{d})$

\begin{tabular}{|c|c|c|c|c|c|c|c|c|c|c|c|}
\hline \multirow{2}{*}{ Enzyme } & \multirow{2}{*}{ Microorganism } & \multirow{2}{*}{ Strain No. } & \multirow{2}{*}{ Genotype - } & \multicolumn{4}{|c|}{ Compound No. } & \multirow{2}{*}{ CAZ } & \multirow{2}{*}{ CTX } & \multirow{2}{*}{ AZT } & \multirow{2}{*}{ IPM } \\
\hline & & & & $4 a$ & $4 b$ & $4 c$ & $4 d$ & & & & \\
\hline \multirow[t]{2}{*}{ Non producing } & S. aureus & ATCC25923 & & 8 & $\leqq 0.25$ & $\leqq 0.25$ & $\leqq 0.25$ & 4 & 0.5 & $>128$ & $\leqq 0.25$ \\
\hline & E. coli & ATCC8739 & & 2 & 16 & $\leqq 0.25$ & 1 & $\leqq 0.25$ & $\leqq 0.25$ & $\leqq 0.25$ & $\leqq 0.25$ \\
\hline \multirow[t]{2}{*}{ PCase (Class A) } & S. aureus & ATCC13150 & & 8 & 0.5 & $\leqq 0.25$ & $\leqq 0.25$ & 8 & 1 & $>128$ & $\leqq 0.25$ \\
\hline & K. pneumoniae & ATCC10031 & & $\leqq 0.25$ & 2 & $\leqq 0.25$ & 0.5 & $\leqq 0.25$ & $\leqq 0.25$ & $\leqq 0.25$ & $\leqq 0.25$ \\
\hline \multirow[t]{2}{*}{ ESBLS } & E. coli & KU4895 & Kit-1 & $>128$ & $>128$ & $>128$ & $>128$ & 2 & $>128$ & 16 & $\leqq 0.25$ \\
\hline & E. coli & KU3733 & Toho-1 & $>128$ & $>128$ & $>128$ & $>128$ & 4 & $>128$ & 16 & $\leqq 0.25$ \\
\hline \multirow[t]{3}{*}{ Metallo (Class B) } & E. coli & & IPM-1 & 128 & $>128$ & 32 & $>128$ & 128 & 64 & $\leqq 0.25$ & 1 \\
\hline & P. aeruginosa & & IPM-7 & $>128$ & $>128$ & $>128$ & $>128$ & $>128$ & $>128$ & 16 & $>128$ \\
\hline & $P$. aeruginosa & & VIM-2 & $>128$ & $>128$ & $>128$ & $>128$ & $>128$ & $>128$ & 16 & $>128$ \\
\hline \multirow[t]{2}{*}{ CEPase (Class C) } & Aci. calcoaceticus & ATCC19606 & & 64 & $>128$ & 32 & 64 & 8 & 16 & 16 & $\leqq 0.25$ \\
\hline & Aci. anitratus & NCTC7844 & & 128 & $>128$ & 64 & $>128$ & 8 & 32 & 32 & $\leqq 0.25$ \\
\hline \multirow[t]{2}{*}{ OXA (Class D) } & P. aeruginosa & & OXA-15 & $>128$ & $>128$ & $>128$ & $>128$ & 128 & 32 & 8 & 1 \\
\hline & P. aeruginosa & & OXA-16 & $>128$ & $>128$ & $>128$ & $>128$ & $>128$ & 32 & 8 & 1 \\
\hline
\end{tabular}

Abbreviation: PCase, penicillinase; ESBL, extended-spectrum $\beta$-lactamase; Metallo, metallo $\beta$-lactamase; CEPase, cephalosporinase; OXA, oxacillinhydrolysing $\beta$-lactamase; AZT, aztreonam; IPM, imipenem.
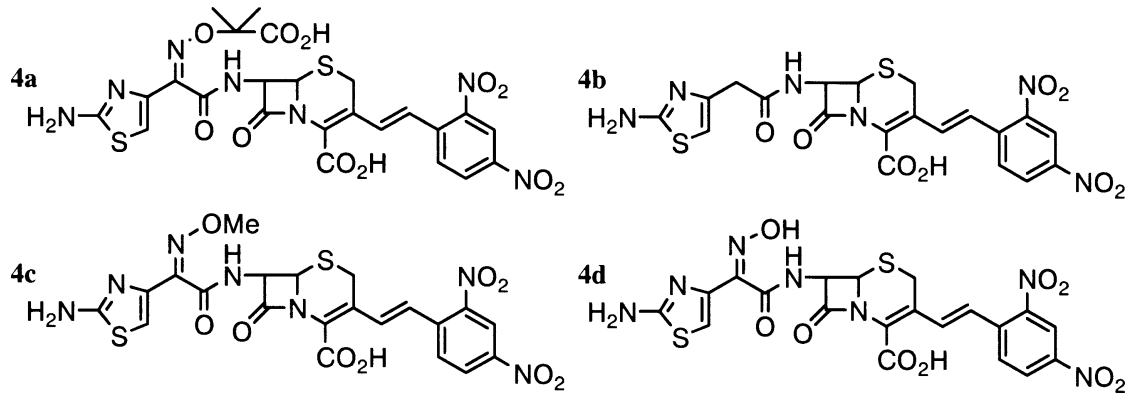

cephalosporinase weakly. Compound $\mathbf{4 b}$ that does not have oxyimino group reacted with all $\beta$-lactamases and a color was changed to red. Subsequently, we investigated whether it is possible to distinguish metallo $\beta$-lactamases from ESBL by sodium mercapto acetic acid (SMA). Metallo $\beta$ lactamases is inhibited by chelating agent such as EDTA or SMA, and according to Hanaki $[4,5]$, the inhibition of metallo $\beta$-lactamases of SMA was stronger than EDTA. And all compounds were escaped from the action of metallo $\beta$-lactamases in the presence of SMA. In the tests, it was confirmed that the compound which has alkoxyimino group inhibited $\beta$-lactamases but the $4 \mathrm{a}$ which has carboxypropyloxyimino group showed the best specificity for ESBL and mutant $\beta$-lactamases and that the compound can be applied to differentiate metallo $\beta$-lactamase from the other $\beta$-lactamases by use of SMA. Now, we are providing simple strip test for screening ESBL and metallo $\beta$-lactamase from traditional penicillinase and cephalosporinase, and we believe that those kinds of test kits are useful in routine work in laboratory.

\section{References}

1. Jacoby GA. Epidemiology of extended-spectrum $\beta$ lactamases. Clin Infect Dis 27: 81-83 (1993)

2. O'callaghan CH, Morris A, Kirby SM, et al. Novel method for detection of $\beta$-lactamases by using a chromogenic cephalosporin substrate. Antimicrob Agents Chemother 4: 283-288 (1972)

3. National Commitee for Clinical Laboratory Standards. 1997. Methods for dilution antimicrobial susceptibility tests for bacteria that grow aerobically. NCCLS document M7-A4. National Committee for Clinical Laboratory Standards, Wayne, Pa.

4. Hanaki H, Kubo R, Murata A, Yamazaki H, Sunakawa K. Novel chimical compound for detecting ESBLs. 103rd American Society for Microbiology General Meeting; Washington DC. Presentation No. A-056, 2003

5. Hanaki H, Kubo R, et al. Characterization of HMRZ-86: a novel chromogenic cephalosporin for detection of extendedspectrum $\beta$-lactamases. J Antimicrob Chemother 53: 888889 (2004) 


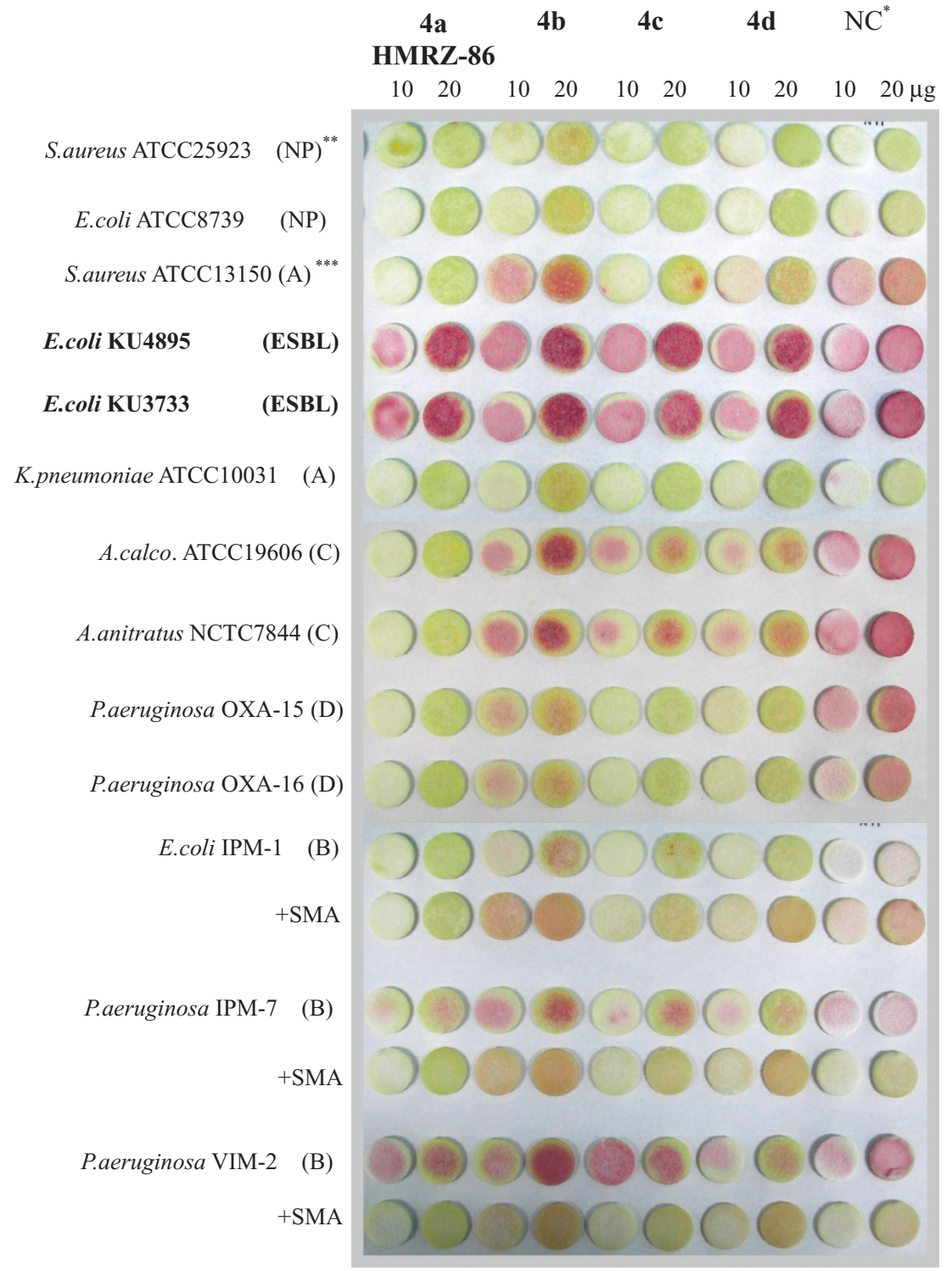

Fig. 2 Disc color pattern of synthetic compounds against $\beta$-lactamases. ${ }^{*} \mathrm{NC}$ : Nitrocefin, ${ }^{*}$ NP: $\beta$-lactamase nonproducing, ${ }^{* *}(\mathrm{~A})-(\mathrm{D})$ : class of each $\beta$-lactamases. 